\title{
AS DUAS EXTREMIDADES DOS SISTEMAS DE INFORMAÇÃO (SI) E AS QUESTÕES RELACIONAIS DE GÊNERO'
}

\author{
Cristina Tavares da Costa Rocha ${ }^{2}$ \\ ctavares@ppgte.cefetpr.br \\ Marilia Gomes de Carvalho ${ }^{3}$ \\ carvalho@ppgte.cefetpr.br
}

\begin{abstract}
RESUMO
Os Sistemas de Informação (SI) apresentam duas extremidades. Em uma, há @s produtor@s de softwares (SW), iniciador@s do processo que se desencadeia, tanto de informação, de intercâmbio, quanto de outras atividades, como programação de portais na Internet, por exemplo. Na outra, há @s usuári@s finais dos SI. Este estudo objetiva tecer reflexões a partir das abordagens relacionais de gênero sobre atividades desenvolvidas nessas duas extremidades, visando a detectar se há diferenças significativas entre ess @ $\mathrm{s}$ atores/atrizes nos cenários digitais no que se refere a produzir $x$ usar as novas tecnologias da informação e da comunicação.
\end{abstract}

\section{INTRODUÇÃO}

Antes de entrar no tema da pesquisa propriamente dito é necessário se fazer ressalva de que ela ainda está em andamento. Portanto, as considerações parciais - principalmente no que se refere ao universo da produção de SW - apontadas neste texto devem ser encaradas como preliminares, visto o caráter exploratório de que ela se reveste nestes momentos iniciais da investigação.

Isto posto, parte-se da constatação de que parcela significativa da sociedade tem vivido conectada em redes de trabalho e lazer nesta Era da Informação. Caracteriza-se como uma sociedade complexa, interligada, regrada e "formatada" pela conexão com diversas outras sociedades e comunidades, através principalmente das novas tecnologias da informação e da comunicação (CASTELLS, 1999). Estudar, pesquisar e refletir sobre @s integrantes de algumas dessas comunidades assim caracterizadas e identificadas por este perfil de indivídu@ nov@ que se delineia e se define, e mais precisamente@s envolvid@s nos processos de produção dos sistemas de informação (SI) e de comunicação, é o objetivo deste trabalho.

Uma das principais motivações para o desenvolvimento desta pesquisa surge após a defesa da dissertação de Mestrado no Programa de PósGraduação em Tecnologia (PPGTE), realizado no Centro Federal de Educação

1 Trabalho aceito e apresentado oralmente no Congresso Internacional "Fazendo Gênero V", ocorrido na Universidade Federal de Santa Catarina (UFSC) de 08 a 11 de outubro de 2002. Sessão 13 "Educação, Tecnologia e Gênero",

2 Graduada em Jomalismo (SP) e Mestre em Tecnologia pelo CEFET-PR.

3 Graduada em Antropologia/Sociologia e Pós-Graduada em Multiculturalismo pela Compegnie da França. 
Tecnológica do Paraná (CEFET-PR), desenvolvido na linha de pesquisa: Tecnologia e interação. A investigação refere-se ao estudo etnográfico da primeira rede de Internet pública implantada no Brasil. Os artefatos tecnológico-computacionais foram vistos, nessa dissertação, como mediadores das atividades humanas, e a Internet foi entendida como contexto, locus de prática, linguagem e atividade; é moldada e, ao mesmo tempo, molda os seres humanos.

Esta pesquisa priorizou o entorno das tecnologias em contextos em que foram introduzidos SI. Embora o estudo nesses locais não esteja esgotado, tendo em vista os diversos viéses que aí podem ainda ser investigados, sentese necessidade de intensificar, nesse momento, a pesquisa mais precisamente na produção dos SW propiciadores da utilização e navegação nos espaçoS virtuais, por causa da exposição dos cenários da sociedade em rede na Era da Informação expostos no trabalho e, principalmente, porque parece estar aí o principal foco das questões relacionais de gênero em sua imbricação com a tecnologia centrada nos sistemas de informação e de comunicação. Ao se fazer reflexões, a posteriori, sobre gênero e tecnologia, os resultados obtidos serviram como provocadores para pesquisas futuras, em oposição a conclusões finais e totalizantes, visto terem sido identificadas as duas extremidades dos SI: @s usuári@s finaise @s produtor@s de SW: CD-ROM e Internet.

\section{UMA DAS EXTREMIDADES DOS SI: @s Usuári@s Finais O Cenário da Primeira Fase da Pesquisa: Os Faróis do Saber de Curitiba}

Em uma das extremidades, estão@s usuári@s finais dos SI. O cenário da pesquisa são os Faróis do $S_{a b e r}{ }^{4}$ (FS) informatizados de Curitiba-PR. O marco teórico centrou-se nas comunidades de prática ${ }^{5}$ e respectiva teoria social do aprendizado e na vida social dos documentos. A metodologia privilegiou a qualitativa de cunho interpretativo, com opção por entrevistas semi-estruturadas e estudo de caso. Foram entrevistad@s quarenta e nove usuári@s, sendo que@s freqüentador@s dos Faróis centrais são da classe média e @s de periferia, da classe baixa. Destes, 22 do sexo masculino e 27 do feminino. Estes números evidenciam um certo equilíbrio entre os gêneros, percebido durante todo o desenrolar da investigação. E também reforçam os dados recebidos do Instituto Curitiba de Informática (ICI), provedor de acesso aos SI e parceiro da Secretaria Municipal da Educação (SME) no projeto "Digitando o Futuro". Os dados apontam que 60\% d@s usuári@s dos SI

${ }^{4}$ Faróis do Saber são minibibliotecas públicas ( 45 ao todo) espalhadas pelo centro e periferia da cidade de Curitiba-PR

5 Comunidade de prática é definida por um agnupamento de pessoas envolvendo relações de prática em três dimensões: 1) empreendimento conjunto; 2) envolvimento mutuo nas práticas, através de niveis diferenciados de participação nas atividades desenvolvidas na comunidade; e 3) repertório compartilhado que facilita o entendimento para o desenvolvimento das práticas. Esta expressão emergiu de estudos antropológicos envolvendo situações de aprendizado (LAVE \& WENGER, 1991; WENGER, 1998 e 1999). 
implantados nos FS são homens e $40 \%$ são mulheres. Os números obtidos pelo $\mathrm{ICl}$ tiveram por base as planilhas referentes aos meses de outubro, novembro e dezembro de 2000 , e a amostragem abrangeu 18 (dos 23) FS informatizados. O padrão característico do mês de outubro se manteve nos meses subseqüentes até o momento das entrevistas com o $\mathrm{ICl}$, que foram feitas em janeiro de 2001. Apesar do alerta dado pelos próprios coordenadores do $\mathrm{ICl}$ sobre certa imprecisão desses dados, considerados preliminares, pois o sistema computacional está ainda sendo implantado e em fase de teste, e ainda pelo escasso tempo decorrido entre a implantação dos SI nos primeiros FS e a aplicação do teste (seis meses incompletos), incluindo o aspecto específico sobre gênero, o levantamento feito pela pesquisadora apontou semelhança com os dados estatísticos obtidos pelo $\mathrm{ICl}$.

A faixa etária dos informantes variou amplamente, desde crianças com cinco anos (duas meninas) até pessoas com 49 anos de idade (duas mulheres). No entanto, como dado obtido pelas observações colhidas in loco e anotadas no diário de campo, pode-se afirmar que pessoas com idades acima de 60 anos, de ambos os sexos, também têm o hábito de freqüentar os FS e de utilizar os computadores e periféricos - mouse, teclado, impressora, monitor, etc. - para realizar as suas atividades, acessando os SI, embora seja um fato mais raro. A maioria d@s usuári@s dos SI nas minibibliotecas públicas não apenas encontra-se na faixa etária infanto-juvenil - visto 24 entrevistados terem de cinco a vinte anos -, como também pertence à classe estudantil, pois está cursando ou concluiu o segundo grau.

Há evidências levantadas por esta pesquisa ${ }^{6}$ de que as questões relacionais de gênero não são observadas significativamente, a exemplo das dificuldades sentidas por est@s usuári@s ao manusear e usufruir das novas tecnologias da informação e da comunicação, dificuldades estas que independem de gênero, faixa etária, etnia e raça, desde que o individuo não seja um analfabeto digital. ${ }^{7}$ Isto porque dessa investigação surgem relatos de ambos os gêneros e tanto de crianças, como adolescentes e mesmo adultos informando que sentiram, em determinados momentos durante o uso dos SI, dificuldades para executarem suas atividades. No entanto, o estudo feito demonstrou que essas dificuldades estão mais centradas na sofisticação ou não das práticas no uso dos SI, istoé, o fato d@s usuári@s serem novatos ou veteranos nas práticas é o que vai diferenciar o grau das dificuidades. Além disso, excluída a questão das práticas, ainda um fator precisa ser levado em consideração: é grande o número de vezes em que as dificuldades não estão centradas n@s usuári@s, mas sim, resultam de falhas técnicas relativas à infra-estrutura da rede, ou oriundas dos provedores de acesso, ou até mesmo da operacionalidade dos próprios sistemas, como lentidão da rede provocada, por exemplo, por sobrecarga de informações de dados, gráficos, etc., ou ainda por manutenção da rede, além de equipamentos que vão se tornando

6 Conforme sugerido anteriormente, esta pesquisa requer aprofundamento no que se refere às questões relacionais de gênero, mesmo com o enfoque n@s usuári@s finais dos SI.

7 Para maiores informaçōes sobre as dificuldades sentidas pel@s usuári@s finais dos SI, ver ROCHA, C.T. da C. (2002) 
obsoletos, ou provocando incompatibilidade quando da introdução de novas partes do conjunto computacional; por quedas nos SI provocadas por falta de energia elétrica, ou descargas estáticas que ocorrem durante fortes chuvas, chegando, inclusive, até à pobreza das interfaces gráficas.

Outras evidências são expressadas nos significados que@s usuári@s dão a essas tecnologias, a exemplo da democratização do acesso gratuito à Internet. A seguir,alguns relatos de informantes de pesquisa levada a efeito em contextos onde foram introduzidos SI - os FS informatizados de Curitiba -, em janeiro de $2001{ }^{8}$

\subsection{Da importância de se estar conectado à Internet:}

Para Emerson (22 anos, 2.․․ Grau Técnico em Telecomunicações) essa importância vem da constatação de que a rede é um show de informação de todos os tipos: (...) é rápido, é prático e eu gosto.

Wilson ( 45 anos, Corretor de Imóveis, 3. ${ }^{\circ}$ Grau incompleto) afirma que essa importância é reflexo do fato de que hoje em dia o computador está ficando igual ao telefone, em termos de importância. Sem ele, fica difícil. Você fica desligado do mundo. Está todo mundo mandando correspondência e recebendo só por computador, comprando, lendo, se informando.

Hortência (38 anos, 2. Grau completo), natural da Espanha; está no Brasil há cerca de três meses. Ela enfatiza que é importante estar conectada à Internet, por sacar información que no se puede conseguir aqui aí tan fácil. Informou que não soube de nada parecido em seu local de origem quanto ao Farol do Saber e o acesso gratuito da população aos meios internéticos e conclui reforçando que lhe parece uma idéia fantástica.

Luciane (29 anos) diz:

É muito importante estar plugada na rede porque eu tenho amigos em outros países, eu tenho parentes em outros estados e para mim se torna muito mais rápido e barato entrar em contato com eles via Internet. [Envio] e-mails mais do que por cartas. E eu detesto escrever cartas. Eu gosto de mandar e-mails, de receber e-mails, acho mais prático (Luciane, 29 anos).

Francisco (26 anos, médico) informa que considera o acesso à Internet muito importante, porque acessa os jornais, alguns programas de escola, para saber o que acontece, por exemplo, na Universidade de São Paulo (USP) ou do Rio de Janeiro-RJ, para saber se vai ter algum curso ou congresso relacionado à [sua] profissão.

\subsection{Custo-benefício / Inclusão e Exclusão Social:}

As questões relativas a custo-benefício da inclusão e exclusão digitalsocial referentes à aquisição de computadores e periféricos emergiram das entrevistas como um forte fator limitador de acesso à maior rede mundial de informação e de comunicação, a Internet. Este fator limitador está presente na fala dos informantes de ambos os gêneros, como Carolina (18 anos,

\footnotetext{
8 Mais informações podem ser obtidas em ROCHA, C.T. da C. (2001).
} 
estudante), que afirma ter computador em casa há uns dois anos, mas não ligado à Internet, porque sai caro; não é todo mundo que pode ter o computador ligado na Internet. Ela diz que costuma freqüentar o Farol do Saber só mesmo para acessar a Internet. Ela grava o que the interessa no disquete e o leva para casa, para continuar a trabalhar lá. Ela ressalta que (...) para isso, o computador que tenho em casa, dá. Ela afirma que sua família já teve acesso à rede através da linha telefônica de sua própria casa, mas nossa conta de telefone subiu bastante; então, tivemos que desistir. Carolina continua seu depoimento:

Há lugares no centro da cidade que cobram RS $\$ 2,00$ (dois reais) para cada quinze minutos de acesso à Internet. Pode-se imprimir quantas páginas quiser, mas elas são pagas. Se bem que na cidade se você paga e é mais rápido, tem as suas vantagens. Mas acho que é muito dinheiro. imagine se você tiver um trabalho para fazer e tiver que usar durante uma semana e ainda tiver que imprimir ... Acho caro (Carolina, 18 anos, estudante).

Assim, Carolina estabelece parâmetros comparativos entre alguns locais de acessos pagos à Internet que ela conheceu e chegou a utilizar e os Faróis do Saber. Nestes, apesar das limitações de horário e de infra-estrutura um tanto quanto desatualizada, além de regras pré-estabelecidas quanto à impressão, e de uso coletivo dos computadores e periféricos, a utilização dos equipamentos e o acesso à WWW são gratuitos.

Luciane (29 anos), diz:

Eu pagava $\mathrm{RS} \$ 4,00$ (quatro reais) ${ }^{10}$ por hora para usar o sistema informacional na Bahia. Não vi outra Internet com acesso público como aqui. Nunca ouvi falar. Eu acho maravilhoso. Para mim é a melhor coisa, porque eu sempre quis estar ligada, para entrar em contacto mesmo com outras pessoas e as coisas que eu preciso, sem ter que pagar (Luciane, 29 anos).

Outro usuário final dos SI nos Faróis do Saber, Francisco (26 anos, médico), afirma:

Eu acho que a maior dificuldade é ter o acesso ao computador porque por mais que hoje ele esteja mais barato ... a Internet, tudo custa. Você tem que pagar o computador, você tem que pagar o provedor, você tem que pagar a linha telefônica. Isso aí dificulta a população, de uma maneira geral, de ter acesso (Francisco, 26 anos, médico).

Portanto, percebe-se que o espectro de preocupações de Francisco é maior do que o de Carolina, na medida em que ele inclui nas despesas totais do acesso à Internet, não apenas a linha telefônica, mas também a compra dos próprios equipamentos, além da intermediação dos provedores de acesso. Como dados adicionais nesse panorama, conforme o indivíduo vai sofisticando

9 O preço mencionado refere-se a dezembro de 2000 e janeiro de 2001, ocasião em que o salário mínimo era de $\mathrm{RS} \$ 151,00$ (cento e cinqüenta e um reais), segundo o DIEESE.

10 O preço citado refere-se ao segundo semestre de 2000. O salário mínimo era de RS\$151,00 (cento e cinqüenta e um reais), nessa época. 
sua opção de acesso, visando, por exemplo, à possibilidade de maior velocidade na transmissão dos dados, maior espaço para memória do computador, impressoras recém-lançadas no mercado, dentre outras sofisticações de opções, mais uma vez os valores implicados nessas aquisições ficam exorbitantes, extrapolando em muito o poder aquisitivo da maioria da população brasileira. Esta é uma dentre várias situações que compõem o quadro de acesso à Internet no Brasil.

Tanto para Carolina ou Luciane, quanto para Francisco ou Mário Jorge (depoimento a seguir), como também para outr@s usuári@s dos SI, os serviços prestados nos Faróis do Saber informatizados significam a possibilidade da inclusão digital-social que, de outro modo, seria uma ilusão para eles. E, em decorrência dessa inclusão social, as possibilidades se ampliam, não apenas quanto aos aspectos pessoais como também profissionais.

Extrapolando os benefícios da computação voltados tão somente para abordagens profissionais, como confecção de currículos "vitae", trabalhos escolares, digitados no Word, produção de e-mails, etc., encontra-se o depoimento de Mário Jorge (17 anos, estudante do $3 .^{\circ}$ ano do $2 .^{\circ}$ grau), que atesta: Eu não tinha as letras e as notas [das músicas que toca] Tinha que comprar na banca e é meio caro. Aqui [no Farol do Saber] eu pego de graça.

Para Mário Jorge, portanto, o acesso à Internet nos Faróis do Saber significa a abertura de possibilidades de acesso ao inesgotável campo da música, suas letras e as suas notas em partituras. Ele se sentia limitado por seus recursos financeiros quando queria comprar os periódicos específicos sobre música nas bancas de jornais e revistas. $O$ acesso gratuito à WWW nos Faróis do Saber não lhe onerava o orçamento doméstico e muito menos a obtenção das letras e das respectivas notas musicais implicavam em custo adicional para ele. Nas suas idas aos Faróis, ele chegava a imprimir cerca de quatro ou cinco músicas por vez.

\section{A OUTRA EXTREMIDADE DOS SI : @s Programador@s}

No entanto, o cenário começa a diferenciar se as observações contemplarem o outro lado da extremidade oposta àslaos usuári@s dos SI, ou seja, na ponta caracterizada pelos bastidores dos cenários digitais, onde se encontram não apenas @s programador@S de SW, mas também @S roteiristas, @s conteudistase@s designers, por exemplo.

Conforme informado no inicio deste texto, a fase que caracteriza esse novo momento da investigação, embora já tenha alguns dados levantados que devem ser encarados como prelimirares, exploratórios -, está ainda em andamento. A pesquisa não está sendo realizada nos próprios FS, visto que a adesão pela SME de parceiros educacionais está em fase muito inicial de implantação". Portanto, no geral, os programas que integram os SI

\footnotetext{
${ }^{11}$ Um desses parceiros educacionais é a Celepar, com ensino e campeonatos virtuais de jogos de xadrez; o CDI, com programas que envolvem informática e cidadania; e a Copel, com o programa "Luz das Letras", destinado a alfabetizar, via infomática, adultos e jovens.
} 
implantados nos FS vêm prontos, compondo o contrato da SME/ICl com a Microsoft.

Desta maneira, opta-se por iniciar exploração de alguns produtores de SW em Curitiba-PR, já incorporando, nessa fase, o marco teórico que integra as relações de gênero em sua imbricação com a Tecnologia computacional. Resgata-se, assim, SCOTT (1995, p. 86), que conceitua gênero como categoria útil de análise sendo elemento constitutivo de relações sociais baseadas nas diferenças percebidas entre os sexos, sendo, também, uma forma primária de dar significado às relações de poder. CARVALHO (2002) que enfatiza a importância do conceito relacional de gênero, priorizando as relações entre homens e mulheres e não uma dicotomia e oposição entre eles e adotando postura teórica que considere polifonia e polissemia que expressam uma pluralidade de modelos, vozes e significados nessas interrelações humanas. Ainda, LERMAN et al. (1997) enfocam gênero como instrumento analítico útil que faz com que a cultura tenha sentido e, conseqüentemente, permite explorar a relação entre a cultura e a tecnologia, a partir de um conjunto de idéias sobre masculinidade e feminilidade e às fronteiras de mudança entre estes. LERMAN et al. (1997), ao sugerir a análise de gênero relativamente à tecnologia, dizem que se deve prosseguir nesse paralelo como construção humana, visto que se sabe muito sobre tecnologia, enquanto estrutura e instituição, porém, pouco sobre tecnologia como parte da identidade cultural ocidental; ou tecnologia como lugar de múltiplos significados, símbolos e ideologias. A análise de gênero seria apenas um começo - embora importante e crucial - para um novo tipo de exploração da tecnologia e cultura.

Nessa fase da investigação adota-se, como na fase anterior, a metodologia qualitativa de cunho interpretativo, com opção pela entrevista semi-estruturada como técnica de pesquisa.

\subsection{A Detecção das Diferenças de Gênero}

Partindo do postulado de trabalho de que há uma lacuna de gênero na área tecnológico-computacional, resgata-se o fato de que, de acordo com 0 U.S. Bureau de Estatísticas de Trabalho dos EUA, a porcentagem das mulheres americanas relativamente aos homens nas carreiras da tecnologia da informação tem declinado ao longo dos 10 a 15 anos. Por exemplo, em 1987, as mulheres eram 36.6\% d@s programador@s de computação nos Estados Unidos. No ano 2001, somente $26.6 \%$; assim, detecta-se uma queda de $10 \%$. Portanto, as mulheres, que constituem mais de metade da população atual geral nos EUA, integram uma porcentagem pequena e desproporcional em relação aos homens no campo da tecnologia da informação. Neste mundo cada vez mais direcionado à computação, há @s produtor@s dos complexos códigos dos programas de computação criando os comandos sobre o que fazer. Com essas ações, podem modelar o que sabemos, como aprendemos, como trabalhamos, além do nosso lazer (CLEMENTS, 2002).

Principalmente no que se refere ao Brasil, questiona-se se a mulher estaria totalmente ausente ou parcialmente "invisivel" nessa área, visto que, segundo SILVA (1998) e SCOTT (1995), a invisibilidade da mulher não significa 
que ela está ausente desses e de outros contextos da tecnologia, como também da Ciência, por exemplo. Assim, pesquisas e estudos dos processos que constróem tecnologias a partir das interrelações sociais são projetos amplos, dificeis envolvendo séria complexidade.

\subsection{O Cenário da Segunda Fase da Pesquisa: Instituição Educacional de Curitiba}

Em Curitiba-PR, em uma grande instituição educacional há o departamento de produção de SW, composto, no geral, por cerca de cento e cinqüenta pessoas. Há o setor que produz o portal, considerado também um tipo de SW, que não o tradicional CD-ROM. Este vende produtos e o portal, integrado no espaço da Internet, vende serviços e alguns produtos. ${ }^{12}$

No início, fazendo jus ao estereótipo da área computacional, como reduto essencialmente masculino, só havia homens trabalhando na produção dos SW. Pouco depois, havia uma única mulher. A segunda mulher da equipe foi Angélica Dutra ${ }^{13}$, psicóloga e educadora, com Mestrado concluído. $\mathrm{Na}$ época, ela foi aceita principalmente pelo perfil que a identifica como da área da Educação. Angélica informa que não tem dúvida de que o Departamento de Programação é [constituído de] quase $100 \%$ de homens. Ao todo, devem ser cerca de 25 pessoas. Ela diz que quando começou a trabalhar no Departamento de Desenvolvimento desta instituição de ensino, em 1998, ela foi a primeira profissional da área da Educação a integrar a equipe de programação de SW educacionais. Angélica descobriu, após algum tempo na empresa que, embora tivesse curso superior como os demais homens que integravam a equipe, na época, além de capacidade e habilidade para trabalhar igualmente comparáveis às deles e compativeis com o perfil exigido para a função, ganhava três a quatro vezes a menos do que os programadores homens e três vezes menos do que os desenhistas da equipe, que eram todos das áreas da Informática e de Desenho. Ela enfatiza que:

Eram as duas equipes que já estavam formadas. Havia umas três pessoas de Desenho (dois desenhistas e um estagiário) e os outros dez, mais ou menos, eram de Programação. Todos com formaçäo superior, e os salários eram bem diferentes que o meu. Muito diferentes. Além das questões envolvidas de gênero, há também questão de preconceito, que é bem importante, que é a ligada à área da Educação. Supostamente, os salários não precisam ser tão altos para quem vem da área da Educação (Angélica Dutra).

Atualmente, o setor, que existe há cerca de quatro anos, produz programas direcionados para as séries $1 .^{2}$ a $4 .^{2}$ com equipe integrada só por programadoras mulheres que preenchem este mesmo perfil de educadora. São as chamadas "conteudistas". Esta equipe só começou a ganhar mais mulheres quando nós começamos a produzir este material, o CD-ROM que

\footnotetext{
12 A diferença básica entre SW para CD-ROM e Internet é que o primeiro o faz pelo meio físico, enquanto que a segunda, através de ambiente virtual Ambos veiculam informações e possibilidades de comunicação.

13 Embora os dados aqui mencionados nâo comprometam os envolvidos, opta-se por usar nomes fictícios, visando a preservar o anonimato dos infomantes.
} 
acompanha o material didático. Caracteriza-se, portanto, como a primeira equipe produtora de SW de $1{ }^{a}$ a $4 .^{a}$ composta só por mulheres, resultado, claro, de seu perfil de educadoras. Reproduz-se, portanto, o esterétipo socialmente construído de que as mulheres são mais aceitas para trabalharem com a faixa etária que compõe as séries $1 .{ }^{a}$ à $4 .{ }^{a}$. Assim, são as continuadoras da educação iniciada nos lares. Situação ortodoxa em todos os contextos escolares do Pais transportada para os meios virtuais.

O setor exclusivo de programação geral é formado só por homens, com exceção de apenas duas mulheres contratadas para fazerem os testes, ou seja, apenas testam para ver se os programas não contêm erros, já que as mulheres seriam consideradas "mais atentas" do que os homens; é uma função que nada exige delas em termos de criatividade ou de concepção dos programas em si. Angélica, ainda uma vez, reforça este fato:

Aqui na área da Programação, as mulheres foram contratadas, pelo menos no Departamento que eu trabalhava, sempre para fazerem testes. Depois que o SW já está desenvolvido e pronto, é só fazer o teste; entrando no programa, teclando nos botõezinhos, clicando e vendo se tudo funciona. Quer dizer que não é uma atividade de produção. Você só vai testar. E supostamente a mulher presta mais atençăo nos detalhes, etc. É bem direcionado (Angélica Dutra).

Situação semeihante ocorre nos EUA, visto uma pesquisa recente levada a efeito pela Technies.com ter demonstrado que as mulheres na área tecnológica ainda ganham menos do que os homens, isto é, cerca de $92 \%$ Disparidades ainda maiores existem em relação às posições gerenciais a de direção no setor de Tecnologias da Informação. De um total de 106.133 profissionais de tecnologia, as mulheres ganharam uma média de US\$5.000 dólares menos do que os homens (NUA, 2001).

\subsection{Dado Novo da Pesquisa: Escolas como usuárias finais dos S!}

Um dado novo surge nessa pesquisa, que é o fato de muitas escolas públicas e particulares serem consideradas usuárias finais dos $\mathrm{SI}$, a partir do ponto de vista dos profissionais dessa área, incorporados por instituições também educacionais maiores. Estas, produzem e vendem os SW, enquanto produtos e serviços, através da aquisição de pacotes fechados caracterizados como os CD-ROMs e, também, através do acesso aos portais educacionais no espaço virtual da Internet, via links adquiridos por contratos legais entre os envolvidos. No entanto, é importante se ressaltar que essas escolas públicas e particulares são também e principalmente as intermediárias entre as grandes instituições de ensino e os alunos, professores, educadores e pais, considerados, nessa cadeia interrelacional, agora sim, e enfim, os usuários finais desses $\mathrm{SI}$.

$\mathrm{Na}$ instituição de ensino referida no início do subitem que informa sobre a segunda fase da investigação, foi criada uma seção sobre "sexualidade" dirigida às turmas de 5. 8. a séries do Primeiro Grau e ao Ensino Médio. Mesmo assim, embora essa seçăo não esteja destacada no espaço das turmas de $1 .{ }^{\mathrm{a}}$ a $4 .{ }^{\mathrm{a}}$, os alunos dessas turmas que acessam as demais séries acabam tendo acesso. Essa seção é um trabalho terceirizado, desenvolvida 
por uma Psicóloga.

Interessante se ressaltar que algumas escolas não quiseram esta seção por não thes interessar e por não thes convir estudar e discutir este tema. Como enfatiza Angélica Dutra: A maioria delas [dessas escolas que não querem este link] é por questões religiosas. A gente não libera essa seção para elas; elas não têm acesso. Na verdade, acho que as [escolas] que limitaram foram as que justamente têm a religião que tem algum tipo de imposição, de dogma. Em gęral, o que a gente tem mais problemas é [com escolas] batistas, adventistas.

É importante se ressaltar, ao se analisar este fato, que estruturalmente trata-se de um meio novo - a Internet - reproduzindo situações velhas, quais sejam, as das escolas como intermediárias na produção do saber. São elas decidindo o que deve ou não ser tema de interesse dos alunos e demais envolvidos no processo educacional. Neste caso, perpetua-se o mito da sexualidade; perpetua-se o tabu deste tema, em pleno alvorecer do século $X X I$, novo momento socio-histórico quando estão sendo consideradas, por parcela significativa da sociedade, de suma importância a adesão a novas posturas de abertura e reflexão deste tema e dos demais dele decorrentes, a exemplo das novas tecnologias da concepção e da reprodução, da homosexualidade, do homoerotismo, temas trazidos à tona com maior ênfase no final da década de sessenta através dos movimentos mais intensos dos travestis, dos gays, das lésbicas, inclusive das resultantes questões éticomorais. Essas escolas, ao proibirem o acesso dos alunos, educadores, pais e professores ao link específico sobre este tema, estão, arbitrariamente, exercendo um poder hegemônico, enquanto agente integrante do esquema de dominação, neste caso, o educacional, como aparelho ideológico do estado (AIE) (FREITAG, 1986, citando ALTHUSSER). As sociedades civis inculcam nos dominados a concepção de mundo dos dominantes de tal maneira que os primeiros a transformam em padrões de orientação de seu próprio comportamento (FREITAG, 1986).

\section{CONSIDERAÇÕES PARCIAIS}

Os resultados das pesquisas, tanto a realizada nos Faróis do Saber informatizados de Curitiba-PR, centrada n@s usuári@s finais dos SI, que evidenciaram que as questões de gênero, classe, etnia, raça e faixa etária, não provocam, em muitas situações vivenciadas nestes contextos, diferenças significativas ao se realizarem atividades mediadas por estes artefatos tecnológico-computacionais; quanto a que está sendo levada a efeito no momento, centrada na outra extremidade dos SI, que é a da produção dos SW, requerem continuidade $\theta$ aprofundamento. Os resultados desta última estão evidenciando fortemente que há diferenças expressivas tanto na contratação desses profissionais quanto no que se refere à sua remuneração nesse segmento do mercado da área computacional. Também, que estão sendo transportadas para os meios virtuais, situações vividas anteriormente à existência dos artefatos tecnológico-computacionais e da Internet, como o fato das escolas continuarem sendo, também nesses meios, mantenedoras de status quo como castradoras de uma educação mais integral dos seres 
humanos nesse novo momento sócio histórico da Humanidade.

Sugerem-se programas educativos que tenham como foco central o estudo, a discussão e a reflexão relacional de gênero na sua imbricação com a tecnologia, voltados diretamente para a capacitação de profissionais mulheres no envolvimento com a tecnologia em geral e mais especificamente com a produção dos programas de SI, minimizando ou excluindo o estereótipo de que este é um reduto exclusivamente masculino, tendo em vista, principalmente, que a tecnologia dos SI teve sua gênese nas ciências exatas.

\section{REFERÊNCIAS BIBLIOGRÁFICAS}

CARVALHO, Marília Gomes de. Relações de gênero e tecnologia: Uma abordagem teórica. Curitiba: Secretaria da Ciência e Tecnologia/CEFET-PR, 2002. (No prelo).

CASTELLS, Manuel. A era da informação - Economia, sociedade e cultura. Vol. I. A sociedade em rede. Säo Paulo: Paz e Terra, 1999.

CLEMENTS, David. What are the theories behind computer technology gender gap? In: Science \& Tech. Disponível em: < http://www.voanews.com/article > Acesso em: 06 set 2002.

DIEESE. Disponivel em: < http://www.dieese.org.br/rel/rac/raffev01.html > Acesso em: 30 set 2001.

FREITAG, Barbara. Escola, estado e sociedade. São Paulo: Moraes, 1986.

LAVE, J.; WENGER, E. Situated learning: Legitimate peripheral participation. New York: Cambridge University Press, 1991.

LERMAN N.; MOHUN, A.; OLDENZIEL, R. Versatile tools: Gender analysis and the history of technology. In: Technology and Culture, v. 38, n. 1, jan 1997, p.1-8. Society for the History of Technology. Também disponivel em:

< http://shot.press.jhu.edu/associations/shot/samplearts/Jan97 > Acesso em: 25 mai 1999.

NUA LTD. Women see glass ceiling in tech sector. Disponivel em:

< http://www.nua.ie/surveys > Acesso em: 19 jun 2001.

ROCHA, C.T. da C. A Informação Via Artefatos Tecnológico-Computacionais nas Comunidades de Prática: Os Faróis do Saber de Curitiba. Dissertação de Mestrado defendida em novembro de 2001 no CEFET-PR.

. As Relações de Gênero e as Dificuldades no Uso dos Sistemas de Informação. In: CARVALHO, M. G. de. (Org.). Gênero e Tecnologia. Curitiba: Secretaria da Ciência e Tecnologia, 2002.

SCOTT, Joan. Gênero: Uma categoria útil de análise histórica. In: Educação e Realidade. Porto Alegre: 20(2): 71-99, jul/dez, 1995.

SILVA, Elizabeth Bortolaia. Tecnologia e vida doméstica nos lares. In: Cadernos Pagu Campinas: Unicamp, (10) 1998: p. 21-52.

Des-construindo gênero em Ciência e Tecnologia. In: Cadernos Pagu Campinas:

Unicamp, (10) 1998: p. 7-20.

SMITH, Emma. History of invention. Disponivel em:

< http://www.news.bbc.co.uk/1/low/technology/2132168.stm> Acessado em 06 ago 2002.

WENGER, E. Communities of practice: Learning, meaning and identity. New York:

Cambridge University Press, 1998.

Communities of practice: Stewarding knowledge. Disponivel em:

< http://www.ewenger.com > Acesso em: 06 nov 1999.

Communities of practice: The key to knowledge strategy. Disponivel em:

< http://www.ewenger.com > Acesso em: 06 nov 1999. 